\title{
Evaluation of Left Atrial Function in Uremic Patients by Speckle Tracing Imaging Evaluation of LA Function in Uremic Pts by STI
}

Fuyong Ye

Gaozhou People's Hospital

Yuwen Yang

Guangzhou First People's Hospital

Yinting Liang

Gaozhou People's Hospital

Jianhua Liu ( $\square$ liujianhua266@163.com )

Guangzhou First People's Hospital

Research

Keywords: uremia, left atrial function, speckle tracking imaging, strain rate

Posted Date: February 17th, 2021

DOI: https://doi.org/10.21203/rs.3.rs-205395/v1

License: @ (i) This work is licensed under a Creative Commons Attribution 4.0 International License.

Read Full License 


\section{Abstract}

Objective: This study aimed to explore the value of speckle tracing imaging (STI) for assessment of left atrial (LA) function in uremic patients.

Methods: One hundred uremic patients were divided into four groups according to the New York Heart Association (NYHA) criteria. Thirty healthy participants were enrolled as a control group. LA functional parameters were determined using conventional echocardiography. The strain rate (SR) curve of LA wall was prepared using STI, and SR in different phases of cardiac cycle were obtained.

Results: The LA maximal volume ( $\left.\mathrm{LAV}_{\text {max }}\right)$ increased and LA passive ejection fraction (LAPEF) decreased. The LA active ejection fraction (LAAEF) showed an initial increase followed by a decrease (all $p<0.05)$. The SR of LA lateral wall and interatrial septum (IAS) in systole (SRs-LA, SRs-IAS) and early diastole (SRe-LA, SRe-IAS) showed a steady decrease; the SR of LA lateral and IAS in late diastole (SRaLA, SRa-IAS) showed an initial increase followed by a decrease. Compared with control group, the SRs-LA and SRs-IAS decreased in four groups with uremia (all $p<0.05$ ). A positive correlation was observed between LAPEF and the absolute value of mean peak early diastolic SR (|mSRe|) $(r=0.862, p<0.05)$, and between LAAEF and the absolute value of mean peak late diastolic SR ( $|\mathrm{mSRa}|)(r=0.756, p<0.05)$. $\mathrm{LAV}_{\text {max }}$ showed a negative correlation with mean peak systolic SR (mSRs) $(r=-0.878, p<0.05)$.

Conclusion: There was a significant correlation between LA function and LA strain rate in uremic patients. STI can allow for an objective and accurate evaluation of LA function in uremic patients.

\section{Introduction}

Previous studies have revealed significant alteration in left atrial (LA) volume and function of patients suffering from chronic renal insufficiency [1]. Several factors associated with uremic state may affect LA structure and function including hypertension, hypervolemia and electrolyte disturbances. Left ventricular diastolic dysfunction can be detected at an early stage by evaluating LA function in uremic patients without left ventricular remodeling [2]. Speckle tracking imaging (STI), a novel ultrasonic technique for objective assessment of myocardial motion, has been used for LA assessment in hypertensive patients. Kokubu et al. found STI useful for quantitative evaluation of LA function in patients with uncomplicated hypertension [3]. Wang et al. demonstrated that in patients with hypertension and paroxysmal atrial fibrillation, longitudinal strain can reflect the structural and functional changes of left atrium [4].

In this paper, we aimed to determine LA strain rate in uremic patients with hypertension. A secondary aim was to explore a new method for evaluation of LA function in uremic patients by demonstrating that LA strain rate correlates with LA function measured by conventional echocardiography.

\section{Materials And Methods}

\section{Patients}


A total of 100 uremic patients (52 male and 48 female; mean age \pm SD, $48.6 \pm 12.8$ years; range, 21-63 years) who qualified the National Kidney Foundation Kidney Disease Outcomes Quality Initiative guidelines (K-DOQI57) diagnostic criteria for end-stage renal disease (ESRD) were selected and divided into four groups according to the New York Heart Association (NYHA) functional classification of cardiac symptoms [symptom class: NYHA I $(n=43)$, NYHA II $(n=28)$, NYH III $(n=16)$, and NYHA IV $(n=13)$ ]. All patients were screened at the Urology Department of our hospital between January 2015 and December 2020. Only patients in sinus rhythm were included. Physical examination, laboratory investigations, electrocardiography, and echocardiography were performed to exclude arrhythmia, rheumatic valvular disease, left ventricular segmental wall motion abnormalities, and congenital heart disease. All uremic patients were on hemodialysis for 4 hours a day, 3 times a week. Patients without standardized treatment were excluded. Each patient underwent assessment by echocardiography before hemodialysis. Thirty healthy volunteers ( 15 male, 15 female; mean age, $45.37 \pm 10.86$ years; range, $22-62$ years) who had no history of renal or cardiovascular disease were included as controls. All subjects in the control group had normal physical examination, echocardiographic, and elecrocardiographic results. The study was approved by the local medical ethical committee and written informed consent from obtained from all patients prior to their enrolment.

\section{Conventional echocardiography}

All uremic patients underwent routine transthoracic echocardiography using Philip IE33 ultrasound system (iE33; Philips Healthcare, Andover, MA) equipped with an S5-1 transducer (1-5 MHz). The left ventricular end-diastolic diameter (LVEDD), interventricular septum thickness (IVST), and LV posterior wall thickness (LVPWT) were obtained by M-mode echocardiography from parasternal long-axis views. The LV ejection fraction (LVEF) was calculated using Bi-plane Simpson formula. These parameters were used to calculate the LV mass index (LVMI) [5, 6] and relative wall thickness (RWT) [7]. The E-wave of mitral valve was measured by pulsed-wave Doppler and the e-wave of the mitral annuli was measured by tissue Doppler imaging. The E/e ratio was calculated as the LV diastolic function parameter.

LA parameters were measured by biplane Simpson's method in the apical two- chamber view, including left atrial maximal volume $\left(L A V_{\text {max }}\right)$, left atrial minimal volume $\left(L A V_{\text {min }}\right)$ and left atrial presystolic volume $\left(\mathrm{LAV}_{\mathrm{p}}\right)$. These parameters were used to calculate the left atrial passive ejection fraction (LAPEF) and left atrial active ejection fraction (LAAEF).

\section{Left atrial speckle tracking analysis}

The standard apical four-chamber images in two dimensional grayscale mode were stored in a cine loop format from three consecutive beats. The patients were told to hold their breath while the images were collected. The LA strain rate was analyzed offline using software Qlab 8.0. Three points, i.e., basal attachment of anterior mitral leaflet, basal attachment of posterior mitral leaflet and the highest point of left atrium, were selected. The endocardium of LA lateral wall and interauricular septum was profiled automatically. Border tracking was adjusted manually if necessary. The following parameters were recorded: peak systolic strain rate of LA lateral wall and interauricular septum (SRs-LA, SRs-IAS), peak 
early diastolic strain rate of LA lateral wall and interauricular septum (SRe-LA, SRe-IAS), and peak late diastolic strain rate of LA lateral wall and interauricular septum (SRa-LA, SRa-IAS). The mean peak systolic SR (mSRs) was calculated as the average of strain rate of LA lateral wall and interatrial septum in systole. The absolute value of mean peak early diastolic SR (|mSRe|) and mean peak late diastolic SR ( $|\mathrm{mSRa}|)$ were obtained by a similar method and converted to absolute value.

\section{Statistical Analyses}

Statistical analyses were performed using SPSS 20.0 software (SPSS Inc, Chicago, IL). All data are expressed as mean \pm standard deviation (SD). Analysis of variance was used for multiple comparisons. Correlations between the variables of interest were assessed using Pearson's correlation coefficient. $P<$ 0.05 was considered statistically significant.

\section{Results}

\section{Comparisons of Regular Measured Values}

Table 1 shows the conventional echocardiographic parameters in uremic patients. We observed that the LVEF decreased with progression of NYHA functional class. LVEDD, RWT and E/e among patients with NYHA class IV were significantly higher than those among patients with the other three NYHA functional classes. However, there were no significant differences between the four NYHA classes with respect to IVST and LVPWT, although all four groups were higher than the control group (Table 1). 
Table 1

Conventional echocardiographic measurements

\begin{tabular}{|c|c|c|c|c|c|c|}
\hline Parameter & $\begin{array}{l}\text { Control } \\
\text { Group }(n= \\
\text { 30) }\end{array}$ & $\begin{array}{l}\text { NYHA Class } \\
\mathrm{I}(\mathrm{n}=43)\end{array}$ & $\begin{array}{l}\text { NYHA Class } \\
\|(n=28)\end{array}$ & $\begin{array}{l}\text { NYHA Class } \\
I I I(n=16)\end{array}$ & $\begin{array}{l}\text { NYHA Class } \\
\text { IV }(n=13)\end{array}$ & $\begin{array}{l}P \text {. } \\
\text { value }\end{array}$ \\
\hline LVEDD & $44.13 \pm 3.32$ & $44.86 \pm 5.66$ & $\begin{array}{l}47.37 \pm \\
5.43^{\mathrm{a}}\end{array}$ & $\begin{array}{l}51.31 \pm \\
4.76^{a, b, c}\end{array}$ & $\begin{array}{l}56.23 \pm \\
4.55^{a, b, c, d}\end{array}$ & 0.000 \\
\hline IVST & $9.43 \pm 0.57$ & $\begin{array}{l}12.82 \pm \\
1.69^{a}\end{array}$ & $\begin{array}{l}12.00 \pm \\
1.62^{\mathrm{a}}\end{array}$ & $12.75 \pm 1.34^{\mathrm{a}}$ & $11.69 \pm 1.80^{\mathrm{a}}$ & 0.000 \\
\hline LVPWT & $9.43 \pm 0.57$ & $\begin{array}{l}12.36 \pm \\
1.92^{\mathrm{a}}\end{array}$ & $\begin{array}{l}11.85 \pm \\
1.51^{\mathrm{a}}\end{array}$ & $12.69 \pm 1.45^{\mathrm{a}}$ & $11.31 \pm 1.80^{\mathrm{a}}$ & 0.000 \\
\hline LVMI & $\begin{array}{l}80.53 \pm \\
10.88\end{array}$ & $\begin{array}{l}128.42 \pm \\
32.95^{\mathrm{a}}\end{array}$ & $\begin{array}{l}131.17 \pm \\
30.80^{\mathrm{a}}\end{array}$ & $\begin{array}{l}160.01 \pm \\
31.16^{a, b, c}\end{array}$ & $\begin{array}{l}163.20 \pm \\
33.33^{a, b, c}\end{array}$ & 0.000 \\
\hline RWT & $0.43 \pm 0.04$ & $0.56 \pm 0.12^{\mathrm{a}}$ & $0.51 \pm 0.09^{b}$ & $0.50 \pm 0.07^{b}$ & $\begin{array}{l}0.41 \pm \\
0.08^{\mathrm{a}, \mathrm{b}, \mathrm{c}, \mathrm{d}}\end{array}$ & 0.000 \\
\hline LVEF & $66.50 \pm 4.93$ & $65.09 \pm 4.60$ & $\begin{array}{l}55.89 \pm \\
3.34^{\mathrm{b}}\end{array}$ & $\begin{array}{l}44.56 \pm \\
2.68^{a, b, c}\end{array}$ & $\begin{array}{l}32.38 \pm \\
5.58^{a, b, c, d}\end{array}$ & 0.000 \\
\hline$E / e$ & $9.53 \pm 1.98$ & $\begin{array}{l}14.20 \pm \\
4.45^{\mathrm{a}}\end{array}$ & $\begin{array}{l}15.61 \pm \\
5.31^{\mathrm{a}}\end{array}$ & $\begin{array}{l}18.68 \pm \\
6.24^{\mathrm{a}, \mathrm{b}}\end{array}$ & $\begin{array}{l}24.17 \pm \\
6.50^{a, b, c, d}\end{array}$ & 0.023 \\
\hline \multicolumn{7}{|c|}{$\begin{array}{l}\text { LVEDD = left ventricular end-diastolic diameter; IVST = interventricular septum thickness; } L V P W T=\text { left } \\
\text { ventricular posterior wall thickness; LVMI = left ventricular mass; } R W T \text { = relative wall thickness; LVEF = } \\
\text { left ventricular ejection fraction. }\end{array}$} \\
\hline \multicolumn{7}{|c|}{${ }^{a} p<0.05$ versus Control Group. } \\
\hline \multicolumn{7}{|c|}{${ }^{b} p<0.05$ versus NYHA Class I. } \\
\hline \multicolumn{7}{|c|}{${ }^{c} p<0.05$ versus NYHA Class II. } \\
\hline${ }^{d} p<0.05 v$ & NYHA Cl & & & & & \\
\hline
\end{tabular}

\section{Comparison of left atrial function}

The $L A V_{\text {max }}, L A V_{\text {min }}$ and $L A V_{p}$ all increased gradually with progression of NYHA functional class. The above three parameters in NYHA Class I were higher than those in the control group. The LAPEF and LAEF all decreased gradually from NYHA Class I to IV. The LAAEF increased in NYHA Class II but decreased in NYHA Class III/IV. The difference between groups was statistically significant. There were no significant difference between the NYHA Class I and the control group with respect to LAPEF, LAAEF and LAEF (Table 2). 
Table 2

Comparison of left atrial volume and function

\begin{tabular}{|c|c|c|c|c|c|c|}
\hline Parameter & $\begin{array}{l}\text { Control } \\
\text { Group }(n= \\
\text { 30) }\end{array}$ & $\begin{array}{l}\text { NYHA Class } \\
\mathrm{I}(\mathrm{n}=43)\end{array}$ & $\begin{array}{l}\text { NYHA Class } \\
I I(n=28)\end{array}$ & $\begin{array}{l}\text { NYHA Class } \\
\text { III }(n=16)\end{array}$ & $\begin{array}{l}\text { NYHA Class } \\
\text { IV }(n=13)\end{array}$ & $\begin{array}{l}P \text { - } \\
\text { value }\end{array}$ \\
\hline $\begin{array}{l}\text { LAVmax } \\
(\mathrm{mL})\end{array}$ & $31.97 \pm 3.91$ & $\begin{array}{l}38.91 \pm \\
8.36^{\mathrm{a}}\end{array}$ & $\begin{array}{l}62.00 \pm \\
12.94^{\mathrm{a}, \mathrm{b}}\end{array}$ & $\begin{array}{l}88.56 \pm \\
10.75^{a, b, c}\end{array}$ & $\begin{array}{l}110.23 \pm \\
7.35^{a, b, c, d}\end{array}$ & 0.000 \\
\hline $\begin{array}{l}\mathrm{LAVp} \\
(\mathrm{mL})\end{array}$ & $18.37 \pm 4.05$ & $\begin{array}{l}25.74 \pm \\
7.07^{a}\end{array}$ & $\begin{array}{l}46.93 \pm \\
13.41^{a, b}\end{array}$ & $\begin{array}{l}71.88 \pm \\
12.45^{a, b, c}\end{array}$ & $\begin{array}{l}94.62 \pm \\
7.00^{a, b, c, d}\end{array}$ & 0.000 \\
\hline $\begin{array}{l}\mathrm{LAV \operatorname {min }} \\
(\mathrm{mL})\end{array}$ & $13.47 \pm 2.81$ & $\begin{array}{l}18.93 \pm \\
5.44^{\mathrm{a}}\end{array}$ & $\begin{array}{l}32.64 \pm \\
13.07^{\mathrm{a}, \mathrm{b}}\end{array}$ & $\begin{array}{l}60.13 \pm \\
15.66^{a, b, c}\end{array}$ & $\begin{array}{l}85.54 \pm \\
7.58^{a, b, c, d}\end{array}$ & 0.000 \\
\hline $\begin{array}{l}\text { LAPEF } \\
(\%)\end{array}$ & $40.60 \pm 9.40$ & $38.32 \pm 4.93$ & $\begin{array}{l}25.43 \pm \\
6.89^{a, b}\end{array}$ & $\begin{array}{l}19.37 \pm \\
5.60^{a, b, c}\end{array}$ & $\begin{array}{l}14.16 \pm \\
2.83^{a, b, c, d}\end{array}$ & 0.000 \\
\hline $\begin{array}{l}\text { LAAEF } \\
(\%)\end{array}$ & $25.70 \pm 4.74$ & $26.73 \pm 5.77$ & $\begin{array}{l}31.93 \pm \\
8.68^{a, b}\end{array}$ & $\begin{array}{l}18.48 \pm \\
10.55^{a, b, c}\end{array}$ & $\begin{array}{l}9.67 \pm \\
1.91^{a, b, c, d}\end{array}$ & 0.000 \\
\hline LAEF (\%) & $57.90 \pm 5.16$ & $55.08 \pm 5.90$ & $\begin{array}{l}48.96 \pm \\
10.84^{\mathrm{a}, \mathrm{b}}\end{array}$ & $\begin{array}{l}33.31 \pm \\
11.66^{a, b, c}\end{array}$ & $\begin{array}{l}22.45 \pm \\
3.30^{\mathrm{a}, \mathrm{b}, \mathrm{c}, \mathrm{d}}\end{array}$ & 0.000 \\
\hline \multicolumn{7}{|c|}{$\begin{array}{l}\mathrm{LAVmax}=\text { left atrium maximal volume; } \mathrm{LAVp}=\text { left atrium pre-systolic volume; } \mathrm{LAVmin} \text { = left atrium } \\
\text { minimal volume; } \mathrm{LAPEF} \text { = left atrium passive ejection fraction; } \mathrm{LAAEF}=\text { left atrium active ejection } \\
\text { fraction; } L A E F=\text { left atrium total ejection fraction. }\end{array}$} \\
\hline \multicolumn{7}{|c|}{${ }^{a} p<0.05$ versus Control Group. } \\
\hline \multicolumn{7}{|c|}{${ }^{\mathrm{b}} \mathrm{p}<0.05$ versus NYHA Class I. } \\
\hline \multicolumn{7}{|c|}{$c_{p}<0.05$ versus NYHA Class II. } \\
\hline${ }^{d} p<0.05 v e$ & s NYHA Clas & & & & & \\
\hline
\end{tabular}

\section{Comparison of left atrial strain rate values}

The strain rate of LA lateral and interatrial septum in systole (SRs-LA, SRs-IAS) and early diastole (SReLA, SRe-IAS) showed a steady decrease from NYHA Class I to NYHA Class IV. The strain rate of LA lateral and interatrial septum in late diastole (SRa-LA, SRa-IAS) was significantly higher in NYHA Class II and significantly lower in NYHA Class III/IV $(P<0.05)$ (Table 3, Fig. 1). The SRs-LA and SRs-IAS in the four groups with uremia were significantly lower than that in the control group (all $p<0.05$ ). However, no significant difference was observed between the NYHA Class I and the control group with respect to SReLA, SRe-IAS, SRa-LA, and SRa-IAS. 
Table 3

Comparison of left atrial strain rate values

\begin{tabular}{|c|c|c|c|c|c|c|}
\hline Parameter & $\begin{array}{l}\text { Control } \\
\text { Group }(\mathrm{n}= \\
\text { 30) }\end{array}$ & $\begin{array}{l}\text { NYHA Class } \\
I(n=43)\end{array}$ & $\begin{array}{l}\text { NYHA Class } \\
\|(n=28)\end{array}$ & $\begin{array}{l}\text { NYHA Class } \\
\text { III }(n=16)\end{array}$ & $\begin{array}{l}\text { NYHA Class } \\
\text { IV }(n=13)\end{array}$ & $\begin{array}{l}P \\
\text { value }\end{array}$ \\
\hline SRs-LA & $2.61 \pm 0.22$ & $2.43 \pm 0.23$ & $2.13 \pm 0.33^{a}$ & $1.81 \pm 0.23^{a, b}$ & $\begin{array}{l}1.51 \pm \\
0.28^{\mathrm{a}, \mathrm{b}, \mathrm{c}}\end{array}$ & 0.000 \\
\hline SRe-LA & $-2.05 \pm 0.17$ & $-2.03 \pm 0.16$ & $-1.64 \pm 0.30^{a}$ & $\begin{array}{l}-1.36 \pm \\
0.27^{a, b}\end{array}$ & $\begin{array}{l}-1.05 \pm \\
0.24^{a, b, c}\end{array}$ & 0.000 \\
\hline SRa-LA & $-2.30 \pm 0.21$ & $-2.30 \pm 0.18$ & $-2.57 \pm 0.24^{\mathrm{a}}$ & $\begin{array}{l}-2.18 \pm \\
0.46^{a, b}\end{array}$ & $\begin{array}{l}-1.45 \pm \\
0.19^{a, b, c}\end{array}$ & 0.000 \\
\hline SRs-IAS & $2.51 \pm 0.15$ & $2.35 \pm 0.19$ & $2.05 \pm 0.23^{a}$ & $1.69 \pm 0.23^{a, b}$ & $\begin{array}{l}1.32 \pm \\
0.23^{a, b, c}\end{array}$ & 0.000 \\
\hline SRe-IAS & $-2.09 \pm 0.22$ & $-2.08 \pm 0.24$ & $-1.63 \pm 0.28^{\mathrm{a}}$ & $\begin{array}{l}-1.37 \pm \\
0.25^{a, b}\end{array}$ & $\begin{array}{l}-1.03 \pm \\
0.19^{a}, b, c\end{array}$ & 0.000 \\
\hline SRa-IAS & $-2.38 \pm 0.12$ & $-2.28 \pm 0.11$ & $-2.46 \pm 0.28^{a}$ & $\begin{array}{l}-2.14 \pm \\
0.44^{a, b}\end{array}$ & $\begin{array}{l}-1.45 \pm \\
0.16^{\mathrm{abc}}\end{array}$ & 0.000 \\
\hline \multicolumn{7}{|c|}{$\begin{array}{l}\text { SRs-LA = peak systolic stain rate of left atrial lateral wall; SRe-LA = peak early diastolic stain rate of } \\
\text { left atrial lateral wall; SRa-LA = peak late diastolic stain rate of left atrial lateral wall; SRs-IAS = peak } \\
\text { systolic stain rate of interatrial septum; SRe-IAS = peak early diastolic stain rate of interatrial septum; } \\
\text { SRa-IAS = peak late diastolic stain rate of interatrial septum; }\end{array}$} \\
\hline \multicolumn{7}{|c|}{${ }^{\mathrm{a}} \mathrm{p}<0.05$ versus Control Group. } \\
\hline \multicolumn{7}{|c|}{${ }^{b} \mathrm{p}<0.05$ versus NYHA Class I. } \\
\hline${ }^{c} p<0.05 v e$ & Is NYHA Cla & & & & & \\
\hline
\end{tabular}

\section{Correlation between LA strain rate and LA function}

There was a significant positive correlation between LAPEF and ImSRe| $(r=0.862, P<0.05)$, and between LAAEF and ImSRa| $(r=0.756, P<0.05)$. LAVmax showed a negative correlation with mSRs $(r=-0.878, P<$ 0.05) (Figs. 2-4).

\section{Discussion}

\section{Left atrial volume and function of uremic patients}


Chronic renal failure is associated with a high incidence of morphological and functional changes in the heart. Cardiac insufficiency is a severe complication of uremia and a major cause of death of uremic patients. Therefore, assessment of heart function at an early stage is a key imperative in patients with uremia, which can guide timely treatment and prolong the patients' survival time. At present, research on patients with uremia at home and abroad is largely limited to the structure and function of the left ventricle [8]. LV diastolic dysfunction is a main manifestation of early cardiac changes in patients with uremia. Several factors such as electrolyte disturbances, renal hypertension and hypervolemia may induce LV stiffness and decrease in compliance. In addition, LV diastolic dysfunction increases left atrial load. To compensate for ventricular dysfunction and to maintain cardiac output, left atrium increases ejection by increasing both atrial pressure and atrial volume. Studies on hypertension and obesity have demonstrated that the changes in LA structure and function occur in the early stage of cardiac insufficiency $[3,9]$. Therefore, evaluation of LA function in uremic patients may help in early detection of abnormal LV diastolic function before LV remodeling. In a study by Vaturi et al., LA function was shown to be related to the exercise capacity in patients with normal LV function [10]. Kokubu et al showed that LA strain rate decreases in patients with hypertension prior to the onset of LA enlargement or LV hypertrophy [3].

The left atrium plays many roles in the cardiac cycle. Firstly, the left atrium acts as a reservoir which receives blood from the pulmonary veins during ventricular diastole and systole. Secondly, left atrium acts as a conduit when blood is sucked into the left ventricle passively during early diastole. Finally, active contraction of left atrium in late diastole reflects the booster pump function [6, 11]. It is widely accepted that $L A V_{\text {max }}$, LAPEF and LAAEF represent the reservoir function, conduit function and booster pump function [12].

In this study, we observed that left ventricle systolic (LVEF) and diastolic (E/e) dysfunction in uremic patients deteriorated with progression of the NYHA functional class (Table 1). The increased pressure in LV end-diastole augmented the left atrial afterload. As a compensatory mechanism, the reservoir function of left atrium enhanced, which was reflected by the gradual increase in $L A V_{\max }$ in our study. Myocardial stiffness caused by uremia reduces the LV active suction capacity [13]. The decrease in LAPEF indicated that LA conduit function declined synchronously with the cardiac function. The increased residual blood in LA activated the Frank-Starling mechanism, as observed by the increased booster pump function in NYHA class II patients [14]. However, the effect of this compensatory mechanism gradually diminished with deterioration of cardiac function, which was reflected in the reduced LAAEF in NYHA class III and IV patients.

It is particularly noteworthy that, compared with the control group, increased LAV was detected in uremic patients with normal cardiac function (NYHA class I) at an early stage, although LAEF had not changed at this time. Previous studies have shown that left atrial enlargement is closely related to the occurrence of adverse cardiovascular events such as atrial fibrillation, ischemic stroke, heart failure, and can be used as an independent predictor of patient death $[15,16]$. Aquaro et al. showed that left atrial remodeling can sensitively reflect left ventricular diastolic dysfunction [17]. 


\section{Left atrial strain rate in uremic patients}

Previous studies have shown that apart from conventional Doppler echocardiography, two dimensional STI can also be used to assess LA structure and function $[18,19]$. The STI can track motional speckle consisting of 20-40 pixels in high frame rate two-dimensional images. Using this new, reliable technique to track speckles on the myocardium, we can obtain the strain rate, which reflects myocardial deformation. Strain refers to the ability of the myocardium to deform, that is, the percentage change in the length of the myocardium from its original length. 2D-STI allows for a more objective and accurate assessment of atrial function as it can distinguish LA motion from that of mitral annulus and ventricle [20]. STI offers an advantage over conventional echocardiography as it can discern subtle changes in the LA wall. Inaba et al. proposed that SRs reflect the reservoir function, while SRe reflects conduit function and SRa reflect the booster pump function on strain rate curve [21]. Changes in LA function in uremic patients can be objectively reflected in the strain rate curve of the left atrium.

In this study, we observed a steady decrease in SRs with progression from NYHA class I to NYHA class IV, which indicates that the stretchability of the atrial wall decreased with enlargement of left atrium. In addition, compared with the control group, we found abnormal SRs in uremic patients with NYHA functional class I. Synchronously, left ventricular stiffness led to ventricular diastolic dysfunction; therefore, $\mathrm{SRe}$, the parameter that represents conduit function, also showed a significant decrease in uremic patients with poor cardiac function. SRa first increased and then decreased, which is consistent with the initial compensatory increase in active systolic function of left atrium followed by its weakening due to cardiac decompensation. Some studies have shown that abnormal myocardial deformation is related to myocardial fibrosis $[22,23]$.

\section{Correlation between LA function and LA strain rate}

Results of correlation analyses showed a strong correlation between LAVmax and SRs, between LAPEF and SRe, and between LAAEF and SRa (correlation coefficient $r=-0.878,0.862,0.756$, respectively). Strain rate is defined as the deformation of myocardium per unit time. The ability of myocardial deformation is an essential factor that influences cardiac systole and diastole. Moreover, the volume and emptying fraction of the left atrium are also affected by preload and afterload. The interaction of cardiac load (external factor) with myocardial motion (an internal factor) affects the volume and function of left atrium [24]. In short, there is a close relationship between LA function and LA strain rate.

\section{Study Limitations}

There were some inherent limitations in this study, including: First, this study focused only on uremic patients with normal sinus rhythm. Left atrial function and strain rate in patients with arrhythmia are yet to be explored. Second, Qlab software used to analyze the LS was originally designed for assessment of left ventricle. However, its use for evaluation of left artial strain has also been validated.

\section{Conclusion}


STI may be used to evaluate LA function in uremic patients. The LA deformation ability may decrease before the onset of overt cardiac insufficiency. The LA function showed a significant correlation with LA strain rate.

\section{References}

1. Kadappu KK, Abhayaratna K, Boyd A, French JK, Xuan W, Abhayaratna W, Thomas L: Independent Echocardiographic Markers of Cardiovascular Involvement in Chronic Kidney Disease: The Value of Left Atrial Function and Volume. J Am Soc Echocardiogr 2016, 29(4):359-367.

2. Kadappu KK, Kuncoro AS, Hee L, Aravindan A, Spicer ST, Suryanarayanan G, Xuan W, Boyd A, French JK, Thomas L: Chronic kidney disease is independently associated with alterations in left atrial function. Echocardiography 2014, 31(8):956-964.

3. Kokubu N, Yuda S, Tsuchihashi K, Hashimoto A, Nakata T, Miura T, Ura N, Nagao K, Tsuzuki M, Wakabayashi $\mathrm{C}$ et al: Noninvasive assessment of left atrial function by strain rate imaging in patients with hypertension: a possible beneficial effect of renin-angiotensin system inhibition on left atrial function. Hypertens Res 2007, 30(1):13-21.

4. Wang Z, Tan H, Zhong M, Jiang G, Zhang $Y$, Zhang W: Strain rate imaging for noninvasive functional quantification of the left atrium in hypertensive patients with paroxysmal atrial fibrillation. Cardiology 2008, 109(1):15-24.

5. Lang RM, Badano LP, Mor-Avi V, Afilalo J, Armstrong A, Ernande L, Flachskampf FA, Foster E, Goldstein SA, Kuznetsova $T$ et al: Recommendations for cardiac chamber quantification by echocardiography in adults: an update from the American Society of Echocardiography and the European Association of Cardiovascular Imaging. Eur Heart J Cardiovasc Imaging 2015, 16(3):233270.

6. Jarasunas J, Aidietis A, Aidietiene S: Left atrial strain - an early marker of left ventricular diastolic dysfunction in patients with hypertension and paroxysmal atrial fibrillation. Cardiovasc Ultrasound 2018, 16(1):29.

7. Gardin JM: The Value of Left Ventricular Relative Wall Thickness in Predicting Ventricular Arrhythmia and Related Death. J Am Coll Cardiol 2016, 67(3):313-315.

8. Hassanin N, Alkemary A: Early Detection of Subclinical Uremic Cardiomyopathy Using TwoDimensional Speckle Tracking Echocardiography. Echocardiography 2016, 33(4):527-536.

9. Yagmur J, Cansel M, Kurtoglu E, Hidayet S, Acikgoz N, Ermis N, Ozyalin F: Assessment of left atrial volume and function by real time three-dimensional echocardiography in obese patients. Echocardiography 2017, 34(2):210-216.

10. Vaturi M, Levine RA, Yosefy C, O'Neil MJ, Picard MH, Hung J: Usefulness of left atrial emptying fraction to predict exercise capacity in patients with normal systolic left ventricular function and without myocardial ischemia. Am J Cardiol 2005, 95(8):1014-1017. 
11. Rudski LG, Lai WW, Afilalo J, Hua L, Handschumacher MD, Chandrasekaran K, Solomon SD, Louie EK, Schiller NB: Guidelines for the echocardiographic assessment of the right heart in adults: a report from the American Society of Echocardiography endorsed by the European Association of Echocardiography, a registered branch of the European Society of Cardiology, and the Canadian Society of Echocardiography. J Am Soc Echocardiogr 2010, 23(7):685-713; quiz 786-688.

12. Soullier C, Niamkey JT, Ricci JE, Messner-Pellenc P, Brunet X, Schuster I: Hypertensive patients with left ventricular hypertrophy have global left atrial dysfunction and impaired atrio-ventricular coupling. $J$ Hypertens 2016, 34(8):1615-1620.

13. Chen R, Zhao BW, Wang B, Tang HL, Li P, Pan M, Xu LL: Assessment of left ventricular hemodynamics and function of patients with uremia by vortex formation using vector flow mapping. Echocardiography 2012, 29(9):1081-1090.

14. Lancellotti P, Moura L, Pierard LA, Agricola E, Popescu BA, Tribouilloy C, Hagendorff A, Monin JL, Badano L, Zamorano JL et al: European Association of Echocardiography recommendations for the assessment of valvular regurgitation. Part 2: mitral and tricuspid regurgitation (native valve disease). Eur J Echocardiogr 2010, 11(4):307-332.

15. Khan MA, Yang EY, Zhan Y, Judd RM, Chan W, Nabi F, Heitner JF, Kim RJ, Klem I, Nagueh SF et al: Association of left atrial volume index and all-cause mortality in patients referred for routine cardiovascular magnetic resonance: a multicenter study. J Cardiovasc Magn Reson 2019, 21(1):4.

16. Nemes A, Kormanyos A, Domsik P, Kalapos A, Lengyel C, Forster T: Normal reference values of threedimensional speckle-tracking echocardiography-derived left atrial strain parameters (results from the MAGYAR-Healthy Study). Int J Cardiovasc Imaging 2019, 35(6):991-998.

17. Aquaro GD, Pizzino F, Terrizzi A, Carerj S, Khandheria BK, Di Bella G: Diastolic dysfunction evaluated by cardiac magnetic resonance: the value of the combined assessment of atrial and ventricular function. Eur Radiol 2019, 29(3):1555-1564.

18. Demir M, Aktas I, Yildirim A: Left atrial mechanical function and stiffness in patients with nondipper hypertension: A speckle tracking study. Clin Exp Hypertens 2017, 39(4):319-324.

19. Sakata K, Uesugi Y, Isaka A, Minamishima T, Matsushita K, Satoh T, Yoshino H: Evaluation of right atrial function using right atrial speckle tracking analysis in patients with pulmonary artery hypertension. J Echocardiogr 2016, 14(1):30-38.

20. Di Salvo G, Pacileo G, Castaldi B, Gala S, Morelli C, D'Andrea A, Limongelli G, Del Gaizo F, Merlino E, Russo MG et al: Two-dimensional strain and atrial function: a study on patients after percutaneous closure of atrial septal defect. Eur J Echocardiogr 2009, 10(2):256-259.

21. Inaba Y, Yuda S, Kobayashi N, Hashimoto A, Uno K, Nakata T, Tsuchihashi K, Miura T, Ura N, Shimamoto K: Strain rate imaging for noninvasive functional quantification of the left atrium: comparative studies in controls and patients with atrial fibrillation. J Am Soc Echocardiogr 2005, 18(7):729-736.

22. Her AY, Choi EY, Shim CY, Song BW, Lee S, Ha JW, Rim SJ, Hwang KC, Chang BC, Chung N: Prediction of left atrial fibrosis with speckle tracking echocardiography in mitral valve disease: a comparative 
study with histopathology. Korean Circ J 2012, 42(5):311-318.

23. Kuppahally SS, Akoum N, Burgon NS, Badger TJ, Kholmovski EG, Vijayakumar S, Rao SN, Blauer J, Fish EN, Dibella EV et al: Left atrial strain and strain rate in patients with paroxysmal and persistent atrial fibrillation: relationship to left atrial structural remodeling detected by delayed-enhancement MRI. Circ Cardiovasc Imaging 2010, 3(3):231-239.

24. To AC, Flamm SD, Marwick TH, Klein AL: Clinical utility of multimodality LA imaging: assessment of size, function, and structure. JACC Cardiovasc Imaging 2011, 4(7):788-798.

Figures
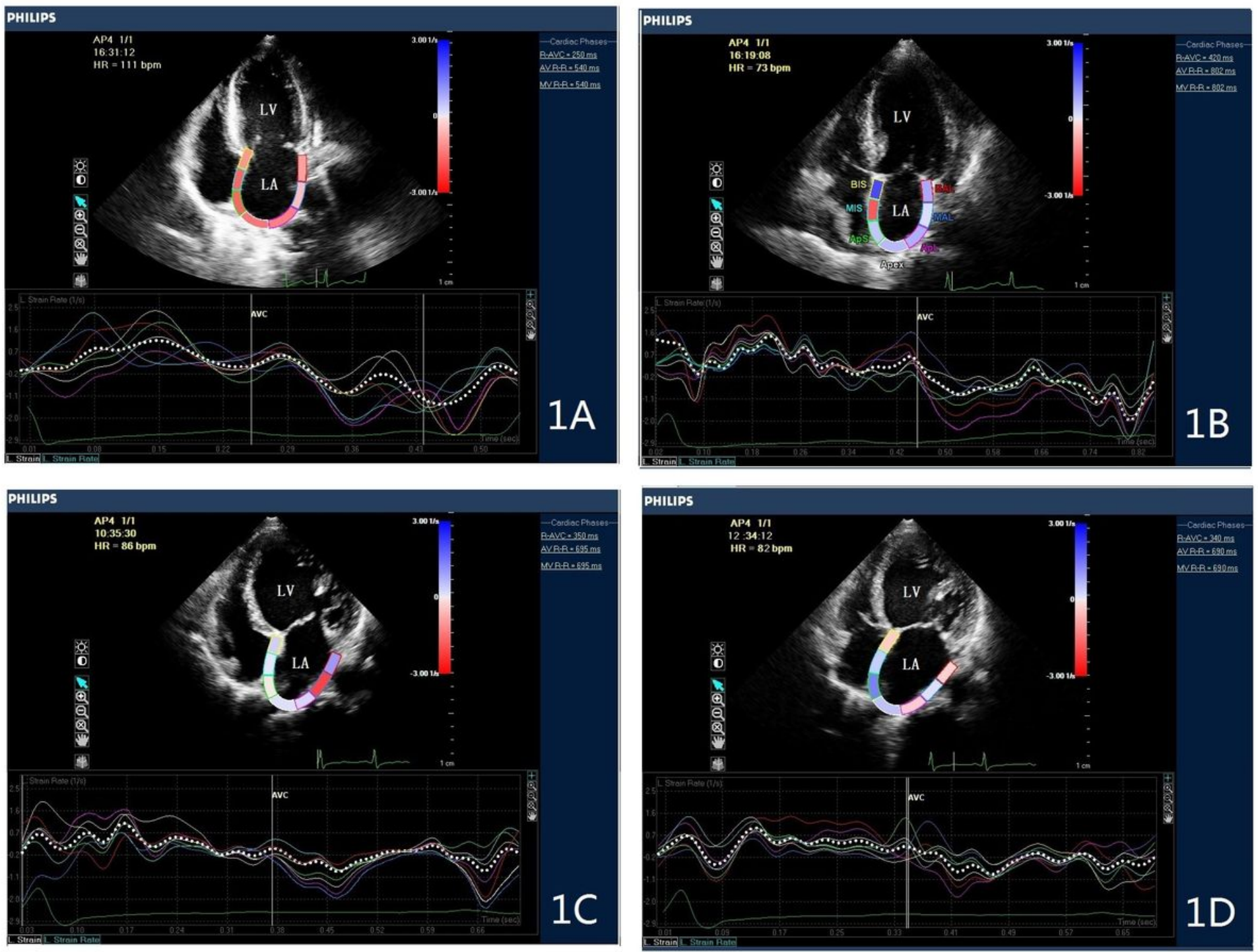

Figure 1

Strain rate of left atrial lateral wall and interatrial septum in uremic patients. A, NYHA Class I; B, NYHA Class II; C, NYHA Class III;D, NYHA Class IV 


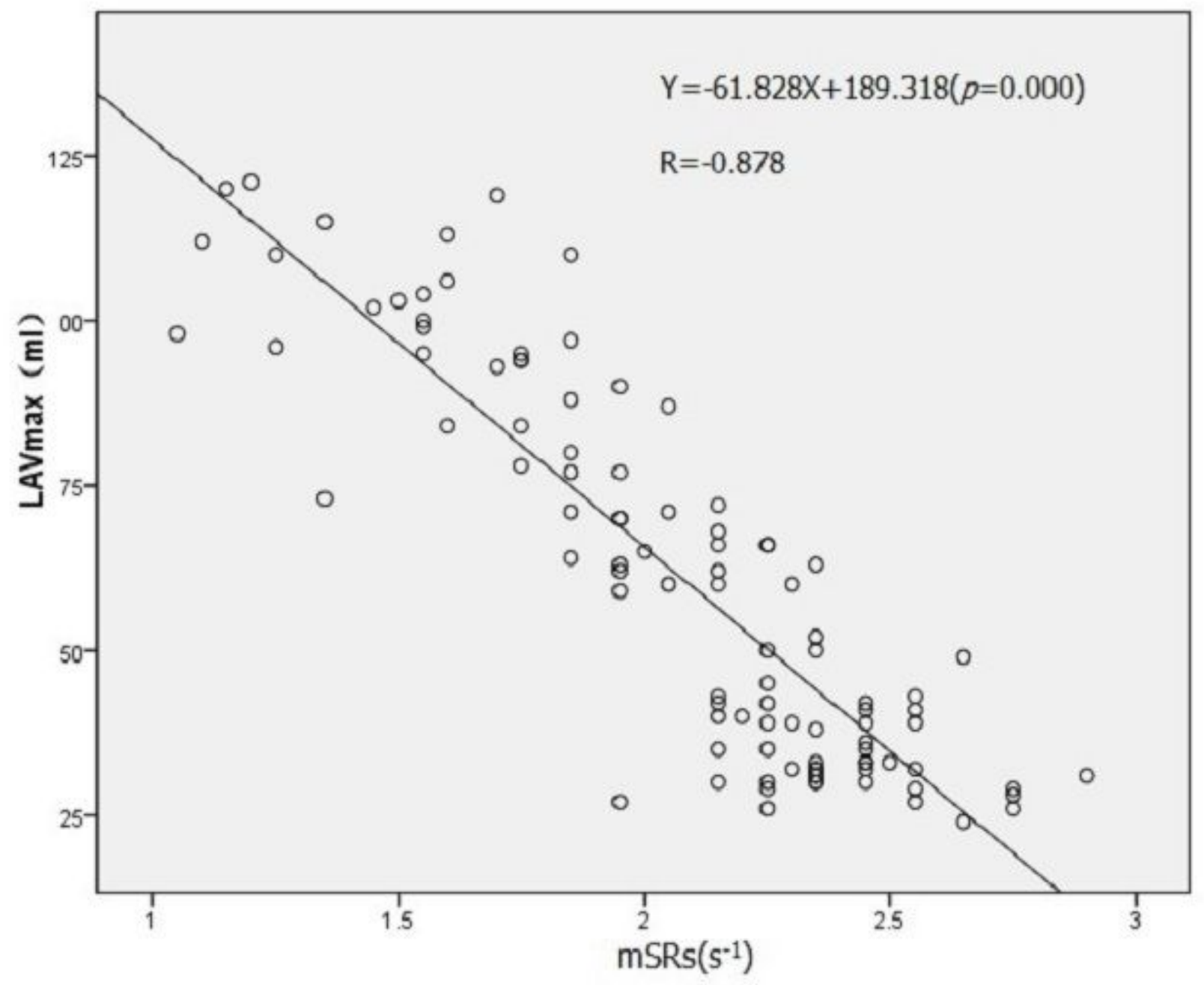

Figure 2

Correlation between LAVmax and mSRs. 


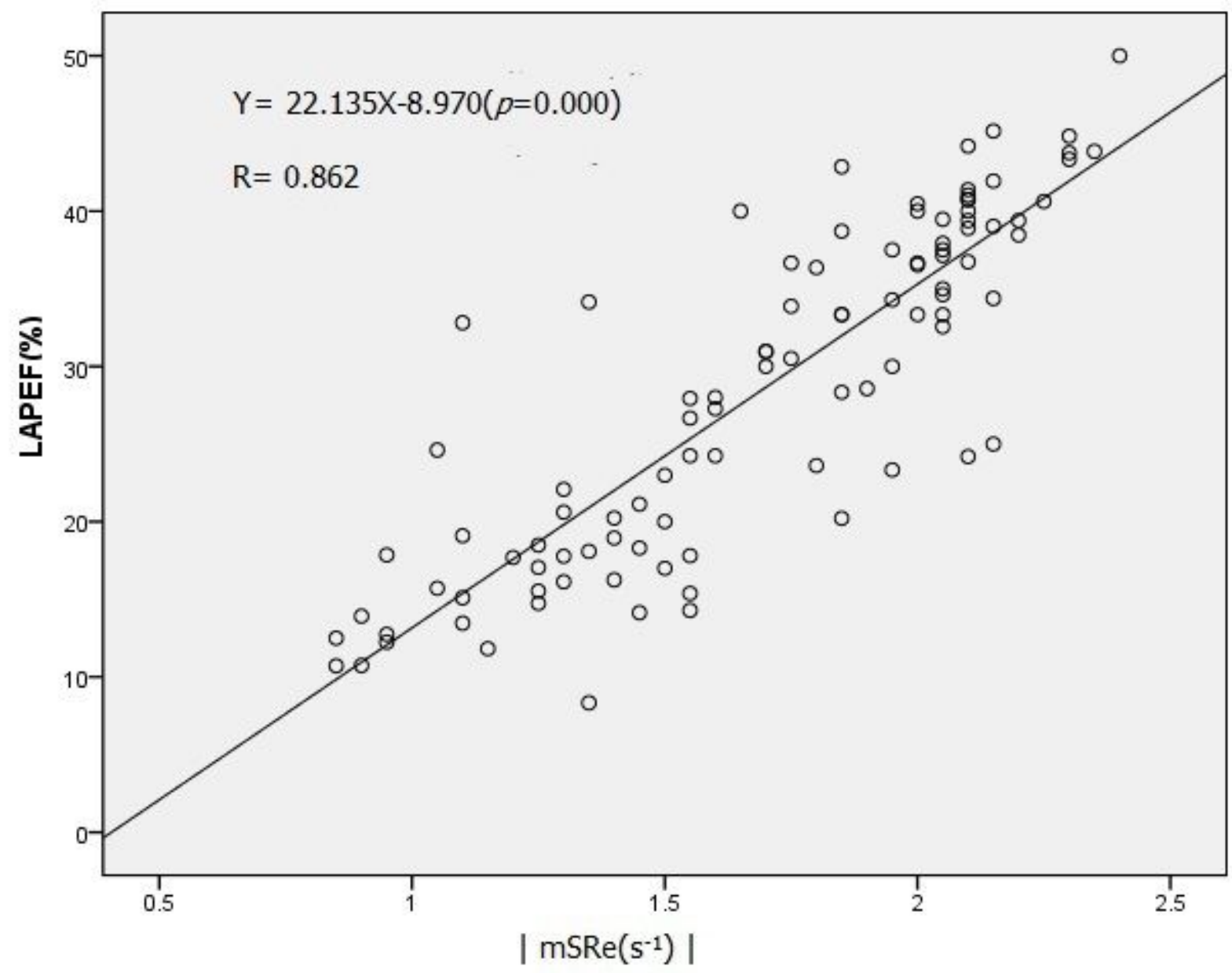

Figure 3

Correlation between LA stain rate (absolute value) and LA function in early diastole. 


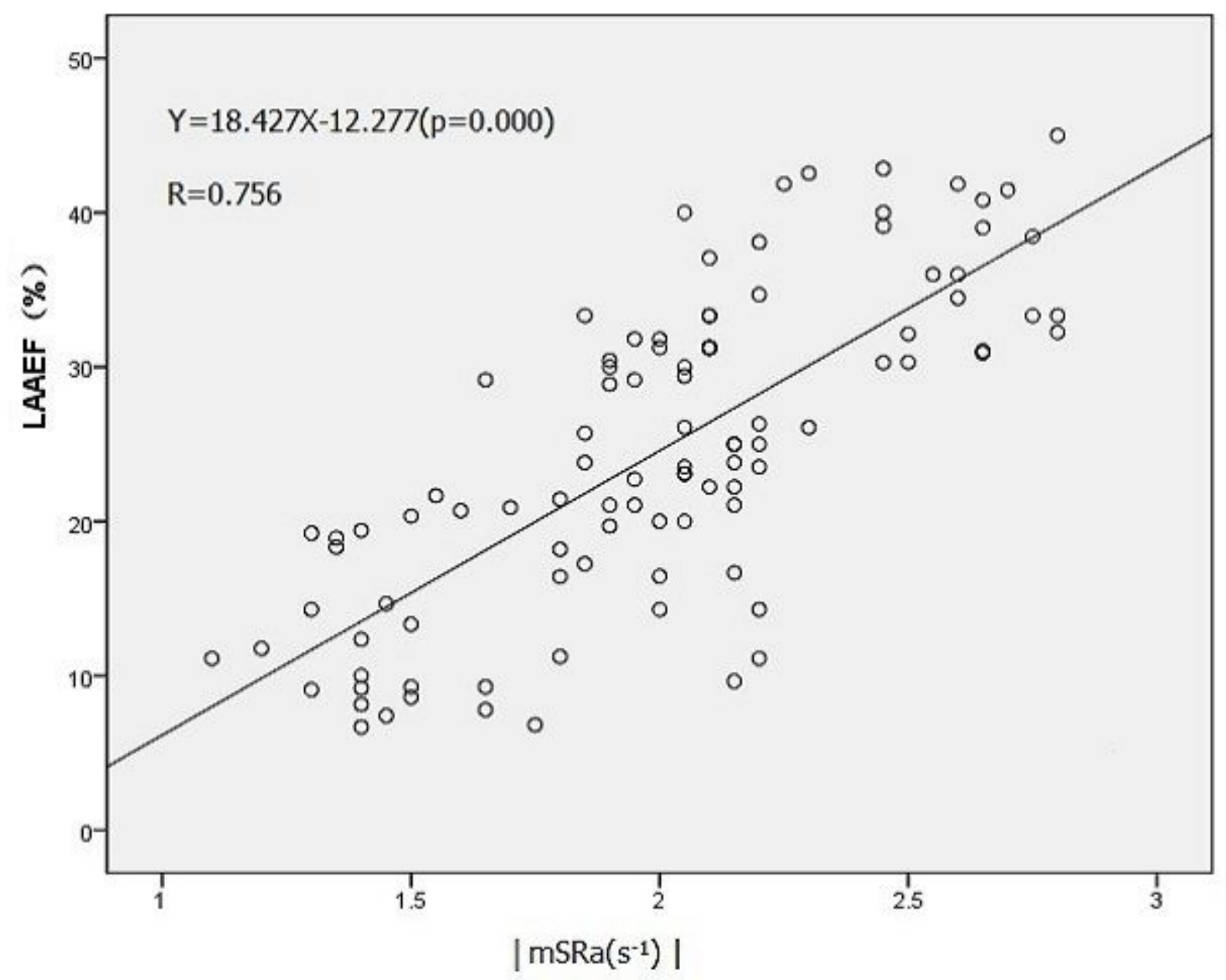

Figure 4

Correlation between LA stain rate (absolute value) and LA function in late diastole 